Demiryolu Mühendisliği

Temmuz 2021

Say1:14, Sayfa: 263-273

Araştırma Makalesi

http://dergipark.or

e-ISSN: 2687-2463, ISSN: 2149-1607

Railway Engineering

July 2021

Issue:14, Page: 263-273

Research Article

\title{
ETCS Seviye-1 Sisteminde Noktasal Hız Tespitine Dayanan Hemzemin Geçit Tasarımının İncelenmesi
}

\author{
Fatih SARIKOÇ® \\ Erciyes Üniversitesi, Mühendislik Fakültesi, Yazılım Mühendisliği Bölümü, Kayseri, Türkiye \\ fsarikoc@erciyes.edu.tr
}

(Alınış/Received: 06.06.2021, Kabul/Accepted: 13.07.2021, Yayımlama/Published: 31.07.2021)

Öz: Bu çalışmada noktasal ve hız aralıklarına duyarlı bir geçit modelinin fonksiyonel tasarımının ETCS (European Train Control System) seviye-1 sisteminde uygulanması incelenmiştir. Bu inceleme geçidin kapalı kalma süresi ve geçit donanım gereksinimi bakımından yapılmıştır. İnceleme sonrası geçidin toplam kapalı kalma süresindeki kısa süreli kazanıma karşın donanım gereksiniminin ve dolayısıyla kurulum maliyetinin belirgin biçimde yükseldiği tespit edilmiştir. İncelenen modelde yüksek maliyete rağmen emniyet ve işletmecilik veriminde zafiyetler etkileri olacağ bulunmuştur. Karmaşık geçit kontrol tasarımları yerine yol alt/üst geçidi yapılması önerilmiştir. Eğer bu mümkün değilse geçit noktasında statik hız profiline göre kapalı kalma süresi kısaltılmış geçit tasarım modelleri uygulanmalıdır.

Anahtar kelimeler: ETCS, Geçit kontrol sistemi, Fonksiyonel tasarım

\section{Investigation of Level Crossing Design Based on Spot Speed Detection in ETCS Level-1 System}

\begin{abstract}
In this study, the application of a functional design of a level crossing sensitive to spot check and speed ranges in the ETCS (European Train Control System) level-1 system was examined. This review has been done in terms of total closure time and hardware requirement of the level crossing. Upon inspection, it was found that despite the short gain in the total closure time of the crossing, the hardware requirement and therefore the cost of its installation increased significantly. In the model examined, it was observed that there may be weaknesses in safety and operational efficiency despite the high costs impacts. It was proposed to build a road underpass / overpass instead of complex level crossing control designs. If this option is not possible, level crossing design models with reduced closure times relying on the static speed profiles in the crossing point must be implemented.
\end{abstract}

Keywords: ETCS, Level crossing control system, Functional design

\section{Giriş}

Hemzemin geçitler, meydana gelen tren kazalarının sıklığı nedeniyle demiryolu taşımacılığının güvenlik bakımından en hassas noktalarından birisidir [1]. Bu nedenle, geçidin türü, hemzemin geçitlerin fonksiyonel tasarımının uygunluğu ve emniyeti önem taşımaktadır. Bir geçit noktasında karayolu alt/üst geçidi veya demiryolu geçidi yapılacağına karar verilirken ilk olarak fayda maliyet hesabı dikkate alınmalı ve analitik gerekçelere dayalı olarak karar verilmelidir. Bu amaçla kullanılan çeşitli analiz yöntemleri bulunmaktadır [2, 3]. Eğer bir demiryolu geçidi yapılması kararı ortaya çıkmışsa TCDD Hemzemin Geçit Yönetmeliği'ne göre emniyet ölçütleri ve trafik yoğunluğu dikkate alınarak geçidin korumalı veya korumasız olacağı belirlenir.

Bariyer korumalı olarak yapılan geçitlerde geçidi etkinleştirme bakımından çeşitli uygulamalar bulunmaktadır. Tasarımı iyileştirme gayretleri farklı dönemlerde farklı geçit fonksiyonların tanımlanmasını beraberinde getirmiştir. Bunlardan bir kısmı treni durdurmayı hedefler. Bazı geçit tasarımları hız tespitini ve bu yolla kapanma süresini kısaltmayı hedefler. Bu tür tasarımlarda 
belirli noktalarda hız kontrolü/ölçümü yapılır ve çeşitli hız aralıklarına bağlı olarak hemzemin geçit etkinleştirilir. Ayrıca treni algılayan farklı türde sistemler de önerilmiş̧tir [4,5].

Bu çalışma belirli hız aralıklarına göre etkinleştirilen bariyerli geçitleri incelemektedir. Birinci bölümde öncelikle geleneksel bir geçit tasarımının temel fonksiyonel özellikleri gösterilmiştir. İkinci bölümde hıza duyarlı geçit tasarım modelleri açıklanmış ve iki farklı senaryo üzerinden bu modeller değerlendirilmiştir. İlk senaryoda en yüksek işletmecilik hızında hareket eden tren için geçidin kapalı kalma süresi, ikinci senaryoda en düşük hızda giden ve sonradan ivmelenen tren için geçidin kapalı kalma süresi incelenmiştir.

Üçüncü bölümde elde edilen sonuçlar üzerinde tartışılmıştır. Son bölümde ise bu çalışmanın sonuç fikri özetlenmiştir. Kapalı kalma sürelerinin karşılaştırmasında ve hesaplanmasında tren uzunluğu ihmal edilmiştir. ETCS seviye-1 sinyal sistemleri [6] ilave donatıları bulunan pahalı bir sistemdir ve bu sistemlerde hıza duyarlı geçit modellerinin kurulum ve bakım maliyetleri yüksektir. Buna karşın hıza duyarlı geçit modellerinin belirgin bir işletmecilik ve emniyet kazanımı bulunmamaktadır.

\section{Metod}

Azami hızı $120 \mathrm{~km} / \mathrm{sa}$ olan hatlar için geleneksel geçit sisteminde, hemzemin geçide yaklaşmakta olan bir tren 45 saniye önceden geçidi etkinleştirir. Tren tespiti ile birlikte sesli uyarı sistemi olan çanlar çalışmaya başlar. Çanlardan 5 saniye sonra bariyer kolları inmeye başlar. Genellikle Türkiye'de bariyer kollarının tümüyle karayolunu kapatması yarım bariyerli geçitlerde 10 saniye, dört bariyerli ve yolu tam kapatan geçitlerde ise 20 saniye sürmektedir. Dört bariyerli ve yolu tam kapatan geçitlerde, önce karayolunun bir yönünü kapatan bariyerler iner, daha sonra diğer yönü kapatan bariyerler inmeye başlar. Böylelikle geçit bölgesinde bir karayolu aracının bariyerler arasında kalması ihtimali daha da azaltılır. TCDD Hemzemin Geçit Yönetmeliği'ne göre demiryolu hemzemin geçit koruma sistemlerinin, demiryolu aracı hemzemin geçide gelmeden en az 25 saniye önce hemzemin geçidi karayolu araç geçişine kapatması gereklidir. Geçidin üzerinde bulunduğu demiryolu sayısının, iki veya daha fazla olması halinde karayolu araçlarının geçit alanını boşaltma süresine bağlı olarak gerekirse bu süre arttırılır.

Belirlenen toplam 45 saniyelik süre ve demiryolunun o hat kesiminde uygulanan en yüksek işletmecilik hızı esas alınarak bir geçidin etkinleştirileceği mesafe hesaplanabilir. Örneğin 120 $\mathrm{km} / \mathrm{sa}$ azami işletmecilik hızı olan bir hat kesiminde, geçitten $1500 \mathrm{~m}$ ötede konumlandırılan ray devresinin meşguliyeti hemzemin geçidi etkinleştirir. Tarif edilen basit yapıda geçit etkinleştirme ve geçit etkinliğini sonlandırma noktaları Şekil 1'de gösterilmiştir.

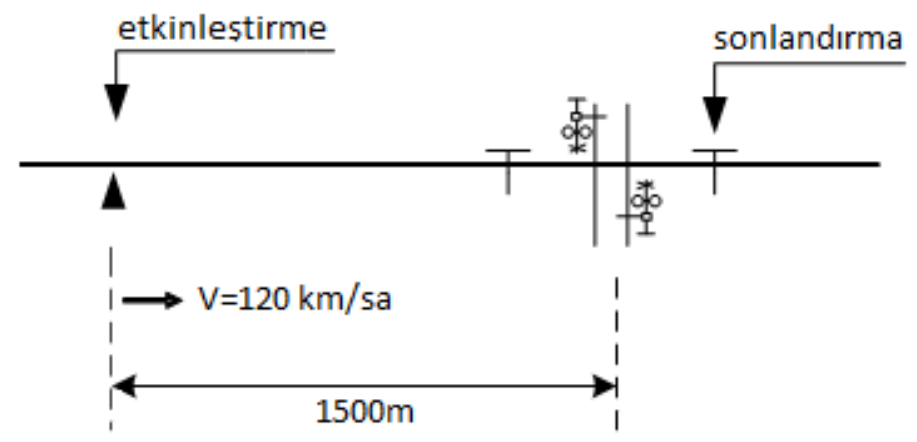

Şekil 1. Geleneksel geçit sistemi 
Geleneksel geçit sistemi tasarımında sabit bir etkinleştirme noktasının kullanılması söz konusudur. Oysa bilindiği üzere hatlarımızda livre hızı $120 \mathrm{~km} / \mathrm{sa}$ olabilen yolcu trenleri ve aynı zamanda azami livre hızı $70 \mathrm{~km} / \mathrm{sa}$ olan yük trenleri işlemektedir. Her durumda aynı noktadan etkinleştirme yapılması özellikle yavaş yük trenlerinde geçitlerin uzun süre kapalı kalmasına neden olmaktadır. Bu olumsuzluğu gidermek amacıyla çeşitli dönemlerde demiryolu hatlarında hız ölçümü yapan ve hıza duyarlı olarak gecikmeli geçit etkinleştirmesi yapan hemzemin geçit tasarımları şartnamelerde tanımlanmıştır.

Hıza duyarlı bir geçit sistemi farklı yaklaşımlarla uygulanabilir. ETCS Seviye-2'de radyo haberleşmesi üzerinden uygulanan hıza duyarlı geçit sistemleri veya geleneksel hatlarda empedans değişimi üzerinden hız ölçümü yaparak geçit sistemini işleten uygulamalar bulunmaktadır.

Bu makalede, noktasal hız ölçümüne dayanan ve sürekli hız ölçümü yapmayan geçit sistemleri incelenecektir. Bu inceleme tek noktadan hız tespiti ve üç noktadan hız tespiti olacak biçimde iki başlık altında yapılmıştır. Tekrardan kaçınmak amacıyla iki noktadan hız ölçümünün incelenmesine gerek duyulmamıştır. Ayrıca yol eğimi, fren intikal süresi, fren gecikme süresi, tren uzunluğu vb. parametreler tüm senaryolarda aynı derecede etkili olacağından incelemeyi basitleştirmek amacıyla göz ardı edilmiştir.

\subsection{Tek Noktadan hıza duyarlı geçit sistemi}

Tek noktadan hıza duyarlı geçit sisteminde geçide yaklaşmakta olan demiryolu aracının hızını ölçecek bir hız tespit aygıtı kullanılır. Bu hız tespit aygıtı bir dingil sayıcı, ray devresi vb. bir sistem alt bileşeni olabilir. Aygıtın ölçtügü hızın anklaşmana gönderilmesi, anklaşmanın hız bilgisine göre gecikmeli veya gecikmesiz bir geçit etkinleştirmesine karar vermesi gerekir.

Böylesi bir tasarımda, hızın ölçüldüğü nokta ile geçidin etkinleştirildiği nokta arasında hız bilgisinin anklaşmana gönderilmesi ve anklaşmandan gelen gecikmeli geçit etkinleştirme bilgisinin geri alınması için yeterli bir mesafe bulunmalıdır. Genellikle 5 saniyelik süre içerisinde ölçülen hızın gönderildiği ve buna karşılık olarak anklaşman bilgisinin geri döndüğü kabul edilir. $t$ olarak gösterilen 5 saniyelik gecikme süresi içerisinde olası en yüksek tren hızı $120 \mathrm{~km} / \mathrm{sa} \mathrm{kabul}$ edildiğinde, trenin alabileceği mesafe en fazla 166,65 m olarak hesaplanır. Şekil-2'de bu yerleşim gösterilmiştir.

Bu modelde, balis noktası ve geçit etkinleştirme noktası aynı noktadır. Bu noktada bulunan balis, geçit flaşörleri ve çan çalışıyorsa izin verilen yaklaşma hızında (Şekil 1 için $120 \mathrm{~km} / \mathrm{sa}$ ) hız kısıtlayıcı bir telegramı trene gönderir. Eğer geçitte bir arıza varsa trene dur bildirisi veren bir telegram gönderir. Balisin bu şekilde kullanımı ETCS'de tanımlı standart bir uygulama değildir. Geleneksel geçit üzerinde ek maliyet gerektiren özel bir çözümdür. Geçit etkinliği flaşör lambalarının akımı üzerinden kontrol edilir. Normalde bariyerlerin inme bilgisi üzerinden geçit kontrolü yapılır. Fakat bu durum etkinleştirme noktasını daha uzağa çekmekle birlikte hıza duyarlı geçit modellerinin incelenmesinde ana fikri etkilemeyecektir. 


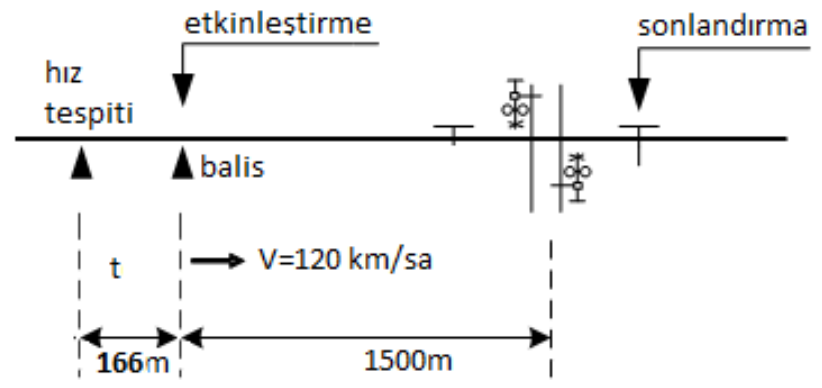

Şekil 2. Tek noktadan hıza duyarlı geçit sistemi

$\mathrm{Bu}$ tasarımda geçidin kapalı kalma süresi iki durum altında gözlenebilir. Birinci durumda, en yüksek hızla geçide yaklaşan ve bu hızda geçide ulaşan bir tren olsun. Diğer durumda en düşük işletmecilik hızı $20 \mathrm{~km} / \mathrm{sa}$ olarak hızla geçide yaklaşan fakat sonradan $1,2 \mathrm{~m} / \mathrm{sn}^{2}$ ivme ile ivmelenerek geçide yaklaşmakta olan tren olsun. İkinci kabulde, varsayılan ivme değeri geleneksel hatta kullanılmakta olan bazı dizilerin kabiliyeti dâhilindedir.

Birinci durumda trenin geçide varma zamanı, mesafe $X=1500 \mathrm{~m}$ ve hız V= $120 \mathrm{~km} / \mathrm{sa}(33,33$ $\mathrm{m} / \mathrm{sn}$ ) için geçidin kapalı kalma süresi

$$
t=\frac{X}{V}
$$

$\mathrm{t}=45$ saniye olarak kolaylıkla doğrulanabilir. Diğer durumda önce basit ivmeli hareket denklemi dikkate alınır. Tren $V_{o}=20 \mathrm{~km} / \mathrm{sa}(5,55 \mathrm{~m} / \mathrm{sn})$ başlangıç hızından $\mathrm{V}=120 \mathrm{~km} / \mathrm{sa}$ son hız değerine $\mathrm{a}=1,2 \mathrm{~m} / \mathrm{sn}^{2}$ ivmesi ile hızlandığında Denklem 2'ye göre

$$
\mathrm{X}=\frac{\mathrm{V}^{2}-\mathrm{V}_{0}^{2}}{2 \mathrm{a}}
$$

$\mathrm{X}=450 \mathrm{~m}$ mesafede en yüksek hıza $(120 \mathrm{~km} / \mathrm{sa})$ ulaşması mümkündür. Bu mesafeyi tren, Denklem 3'e göre 23,15 saniyede kat eder.

$$
\mathrm{t}=\frac{\mathrm{V}-\mathrm{V}_{0}}{\mathrm{a}}
$$

Geriye kalan geçit mesafesini $(1050 \mathrm{~m})$ sabit $120 \mathrm{~km} / \mathrm{sa}$ ile yaklaşık 32 saniyede alır. Bu en düşük hızla geçidi etkinleştiren ancak ivmelenerek geçide yaklaşan trenin geçide varma süresi toplamda yaklaşık 55 saniye olur (Tablo 1). Bu süre aynı zamanda ivmeli hareket dikkate alındığında geçidin en düşük kapalı kalma süresidir.

Tablo 1. Tren yaklaşma senaryoları

\begin{tabular}{cccc}
\hline Durum & $\begin{array}{c}\text { İvmeli Alınan } \\
\text { Yol ve Süre }\end{array}$ & $\begin{array}{c}\text { Sabit Hizla } \\
\text { Yol ve süre }\end{array}$ & $\begin{array}{c}\text { Toplam } \\
\text { Kapalı Süre }\end{array}$ \\
\hline İlk hız $120 \mathrm{~km} / \mathrm{sa}$ & - & $1500 \mathrm{~m}, 45 \mathrm{sn}$ & $45 \mathrm{sn}$ \\
İlk hız $20 \mathrm{~km} / \mathrm{sa}$ & $450 \mathrm{~m}, 23 \mathrm{sn}$ & $1050 \mathrm{~m}, 32 \mathrm{sn}$ & $55 \mathrm{sn}$ \\
\hline
\end{tabular}

Tek noktadan hıza duyarlı geçit tasarımının artısı, anklaşman sisteminin tespit edilen tren hızına göre geçidin etkinleştirme zamanını geciktirebilmesidir. Bu yolla geçidin toplam kapalı kalma 
süresi anklaşman tarafından bir miktar azaltılabilir. Fakat bu geciktirmenin en düşük hızla tespit edilen tren için dahi en fazla 10 saniye olabileceği açıtır.

\section{2. Üç noktadan hıza duyarlı geçit sistemi}

Öncelikle üç noktadan hıza duyarlı geçit modellerinin uygulamada bulunmadığını belirtmek gerekir. Fakat hıza duyarlı geçit modellerinin artan karmaşası, yatırım maliyetlerine karşı emniyet yönünden değerlendirilebilmesi için bu model özellikle incelenmiştir.

Bu modelde hız ölçümünün üç noktadan yapılacağı ve V1=1-40 km/sa, V2=41-80 km/sa, V3=81$120 \mathrm{~km} / \mathrm{sa}$ hız aralıklarına göre geçidin etkinleştirileceği öngörülmüştür (Şekil 3). Her bir hız aralığının üst sınır hız değerinde geçidin 45 saniye önceden kapanmasını sağlayacak mesafeler; $\mathrm{V} 1_{\text {üst }}=120 \mathrm{~km} / \mathrm{sa}$ için $1500 \mathrm{~m}, \mathrm{~V} 2_{\text {üst }}=80 \mathrm{~km} / \mathrm{sa}$ için $1000 \mathrm{~m}$ ve V $3_{\text {üst }}=40 \mathrm{~km} / \mathrm{sa}$ için $500 \mathrm{~m}$ olarak belirlenmiştir. Örneğin hızı 41-80 km/sa aralığında ölçülen bir tren, geçidi $1000 \mathrm{~m}$ ötede bulunan ikinci hız tespit noktasından etkinleştirir.

$\mathrm{Bu}$ uzaklıkların bulunduğu noktalarda birer balis yerleştirilmiştir. $\mathrm{Bu}$ balisler geçit etkinleştirildikten sonra trenin geçide en yüksek ne hızla yaklaşabileceği bilgisini ETCS araçüstü bilgisayara telegram göndererek bildirir. Etkinleştirme gerçekleşmiş ise etkinleştirme noktasından sonra gelen balisler trene herhangi bir hiz kısıtı göndermez. Örneğin 41-80 km/sa aralığında hızı ölçülen bir tren ikinci hız tespit noktasında geçidi etkinleştirdiği andan itibaren 80 $\mathrm{km} / \mathrm{sa}$ hız sınırını geçemez ve üçüncü balis noktasında araçüstü sisteme herhangi bir hız kısıtı gönderilmez.

Hız tespit noktası ve balis noktası arasındaki mesafeler $166 \mathrm{~m}$ ve $111 \mathrm{~m}$ olarak belirlenmiştir. İlk iki hız tespit noktasına trenin $120 \mathrm{~km} / \mathrm{sa}$ hız ile gelme olasılığ vardır. Bu nedenle balise anklaşmandan gelecek bilginin 5 sn gecikmeli olarak yaklaşık $166 \mathrm{~m}$ ulaşabileceği dikkate alınmıştır. Benzer biçimde üçüncü hız tespit noktasına trenin en fazla $80 \mathrm{~km} / \mathrm{sa} \mathrm{hız} \mathrm{ile} \mathrm{gelebileceği}$ dikkate alınarak balis ve hız tespit noktası arasında $111 \mathrm{~m}$ mesafe olması yeterli görülmüştür. Ancak anklaşmandan gelecek bilginin gecikme süresi üretici firmaya göre değişebilmektedir. Ayrıca mühendislik uygulamalarında hesaplanan değerler genellikle bir tolerans değeri eklenerek yukarı yuvarlanır.

Geçidin etkinleşmesine izin verilen hız aralığın üstünde bir hızla trenin geçide yaklaşması istenmez. Bu amaçla geçit daha önceden etkinleştirilmemişse; balisler temsil ettikleri geçidi etkinleştirme noktasına atanan maksimum hız değerini trenin araçüstü sistemine hız kısıtı olarak gönderirler. Bu durumda henüz etkinleştirilmemiş geçit için, birinci balis noktasında hız kısıtı 120 $\mathrm{km} / \mathrm{sa}$, ikinci noktada $80 \mathrm{~km} / \mathrm{sa}$ ve üçüncü noktada $40 \mathrm{~km} / \mathrm{sa}$ olarak araçüstü sisteme gönderilir.

Üçüncü balis noktasına (varsayılan etkinleştirme noktası) gelindiğinde, hız ne olursa olsun geçit sistemi mutlaka etkinleştirilir.

Bu modelde geçidin kapalı kalma süresi iki genel durum altında gözlenebilir. Birinci durumda sabit hızla trenin yaklaşması olsun. Sabit hızla yaklaşan trenlerde bu model gerçekten beklenen verimi gösterir. $81-120 \mathrm{~km} / \mathrm{sa} \mathrm{hız} \mathrm{aralığında} \mathrm{sabit} \mathrm{hızla} \mathrm{yaklaşmakta} \mathrm{olan} \mathrm{bir} \mathrm{tren,} \mathrm{geçidi} \mathrm{birinci}$ hız tespit noktasında etkinleştirir. Eğer $120 \mathrm{~km} / \mathrm{sa}$ sabit hızla devam ederse geçit 45 saniye kapalı kalacaktır. En kötü durumda $81 \mathrm{~km} / \mathrm{sa}$ sabit hızla devam ederse yaklaşık 67 saniye geçit kapalı kalacaktır. 


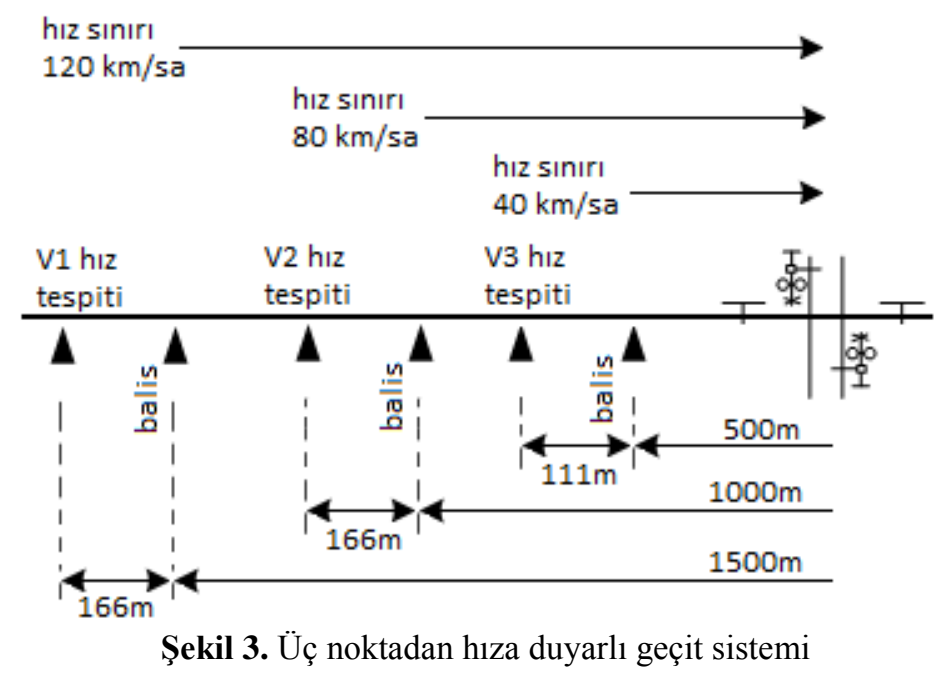

41-80 km/sa hız aralığında sabit hızda yaklaşmakta olan tren birinci hız tespit noktasında geçidi etkinleştirmez, geçit ancak ikici hız tespit noktasında $1000 \mathrm{~m}$ ötede etkinleştirilir. Bu durumda, en iyi halde $80 \mathrm{~km} / \mathrm{sa}$ sabit hızda ilerleyen tren geçidi yine beklendiği gibi 45 saniye kapalı tutar. $\mathrm{Bu}$ hız aralığında en kötü durumda $41 \mathrm{~km} / \mathrm{sa}$ sabit hızda ilerleyen tren geçidi yaklaşık 88 saniye kapalı tutacaktır.

$1-40 \mathrm{~km} / \mathrm{sa}$ hız aralığında sabit hızda yaklaşmakta olan tren birinci ve ikinci hız tespit noktasında geçidi etkinleştirmez, geçidi ancak 500 m ötede bulunan üçüncü hız tespit noktasında etkinleştirir. $\mathrm{Bu}$ aralıkta $40 \mathrm{~km} / \mathrm{sa}$ sabit hızda ilerleyen tren için geçit beklendiği gibi 45 saniye kapalı kalır. Ancak, sınırlı seyir gibi düşük hızlarda yaklaşan bir tren için, örneğin $20 \mathrm{~km} / \mathrm{sa}$ sabit hızda bir tren için, geçidin kapalı kalma süresi 90 saniye olur.

Bu modeli ivmeli hareket altında değerlendirmek karışıktır. Çünkü çok sayıda olasılık söz konusudur. Bu nedenle, çok sayıda olasılık yerine geçidin ivmeli hareketlerdeki başarımını görmek amacıyla başlangıçta çok yavaş ilerleyen fakat sonradan en yüksek ivme ile hızlanan bir trenin geçide olan etkisi incelenmiştir. Bu ETCS araç üstü sistemi bulunan tren için olabilecek en kötü senaryodur. Varsayılan hizlanma ivmesi $1,2 \mathrm{~m} / \mathrm{sn}^{2}$, frenleme ivmesi ise $0,75 \mathrm{~m} / \mathrm{sn}^{2}$ seçilmiştir. Bu değerlerin yeni alınan dizilerin kabiliyetlerini yansıttığını, eski lokomotiflerin ve çeşitli yük treni teşkillerinin daha düşük ivme değerlerine sahip olabileceğini vurgulamakta fayda vardır. Olası daha düşük ivme değerlerinin geçide etkisi tartışma bölümünde değerlendirilmiştir.

İvmeli tren davranışını seçmenin iki amacı vardır. Birincisi, geçidi en uzun süre kapalı tutabilecek durumu değerlendirmektir. Bu değerlendirme yapılırken trenin hızı her ne kadar yavaş ölçülse de trenin sonradan yüksek ivme ile hızlandığı en kötü senaryonun ihmal edilmemesi gerekir. En kötü senaryo dikkate alındığında hızı en yavaş ölçülen tren için geçidin toplam kapalı kalma süresi hesaplanacaktır. İkincisi ani ivmelenmelerde bahse konu modelde trenin geçide beklenenden daha erken gelip gelmeyeceğini görmektir.

Üç çeşit ivmeli hareket ele alınmıştır. Birincisinde, tren $20 \mathrm{~km} / \mathrm{sa} \mathrm{hızında} \mathrm{birinci} \mathrm{tespit} \mathrm{noktasına}$ girer ve bu noktadan sonra ivmelenebilir. İkincisinde, tren $20 \mathrm{~km} / \mathrm{sa}$ hızında ikinci tespit noktasına kadar ilerler ve ikinci tespit noktasından itibaren ivmelenebilir. Üçüncüsünde, tren üçüncü tespit noktasına kadar $20 \mathrm{~km} / \mathrm{sa}$ hızında ilerler ve bu noktadan itibaren en yüksek ivme ile hızlanabilir. Söz konusu üç hareketin geçide yaklaşırken izlediği hız eğrisi Şekil-4’te gösterilmiştir.

İvmeli hareketin birinci durumunda (Şekil 4, hız eğrisi-1) tren ikinci tespit noktasına varmadan önce en yüksek hız değeri olan $120 \mathrm{~km} / \mathrm{sa} \mathrm{hızına} 450 \mathrm{~m}$ de ulaşır. Bu noktadan itibaren $50 \mathrm{~m}$ sabit 
hızla devam eder. İkinci hız tespit noktasına geldiği an derhal geçit etkinleştirilir. Ancak tren hızı beklenen hız aralığından daha yüksektir. Tren balisten gelen hız kısıtı ile birlikte frenleyerek hızını $80 \mathrm{~km} / \mathrm{sa}$ değerine $576 \mathrm{~m}$ mesafe içinde 14,8 saniyede düşürür. Sabit bu hızda geçide yaklaşmasını sürdürür. Böylesi bir hareket grafiğinde geçidin toplam kapalı kalma süresi beklenenden daha kısa yaklaşık 58,3 saniye olarak gerçekleşir.

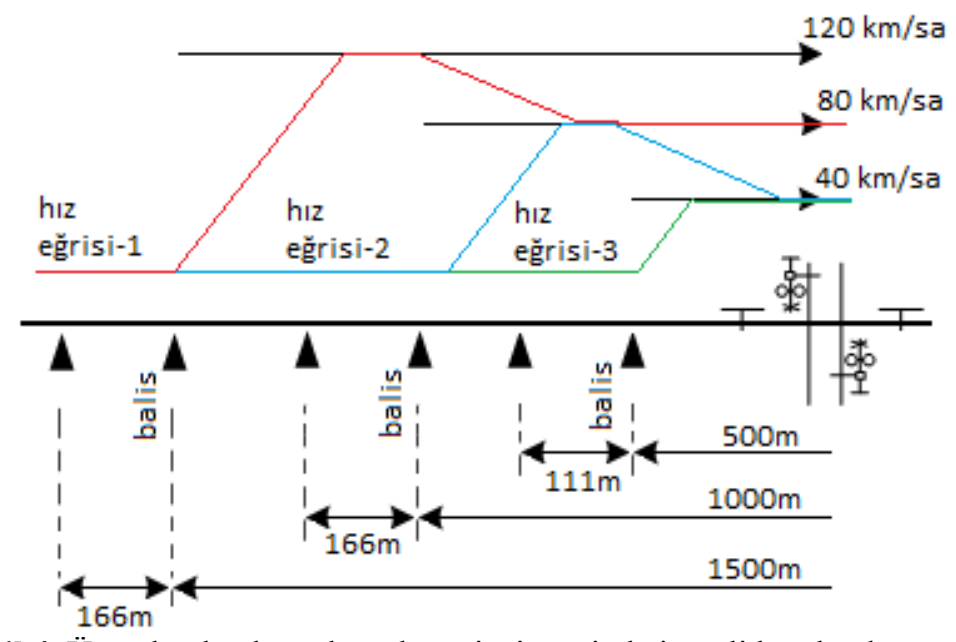

Şekil 4. Üç noktadan hıza duyarlı geçit sisteminde ivmeli hareket hız eğrileri

Benzer şekilde ikinci durumda $20 \mathrm{~km} / \mathrm{sa}$ sabit hızda ikinci hız tespit noktasına gelen tren, tespit noktasında hızı düşük olduğu için geçidi tetiklemez. Kötü senaryoda ikinci tespit noktasından sonra maksimum ivme ile hızlanan tren (Şekil-4, hız eğrisi-2) $193 \mathrm{~m}$ sonra yaklaşık 13,9 saniyede ikinci hız sınır değeri $80 \mathrm{~km} / \mathrm{sa}$ hıza ulaşır. Bu hızda $307 \mathrm{~m}$ mesafeyi yaklaşı 13.8 saniyede alır ve üçüncü hız tespit noktasına ulaşır. Burada bulunan balis yeni hız sınır değerini $40 \mathrm{~km} / \mathrm{sa}$ olarak araç üstü bilgisayara gönderir ve tren frenleme yapar. Tren yaklaş1k $411 \mathrm{~m}$ sonra 14,8 saniyede $40 \mathrm{~km} / \mathrm{sa}$ hızına iner ve geriye kalan $89 \mathrm{~m}$ uzaklığ sabit hızla 8 saniyede alır. Sonuçta, hız eğrisi2’ye (Şekil 4) göre geçidin toplam kapalı kalma süresi 50,5 saniye olarak gerçekleşir.

Üçüncü ivmeli hareket durumunda sabit $20 \mathrm{~km} / \mathrm{sa}$ hızla tren üçüncü hız tespit noktasına kadar ilerler, bu noktadan itibaren ivmelenerek azami $40 \mathrm{~km} / \mathrm{sa} \mathrm{hız} \mathrm{sınırına} \mathrm{yaklaşık} 38,6 \mathrm{~m}$ sonra 4,6 saniyede ulaşır. Geriye kalan yaklaşık 461,4 m uzaklığı sabit hızda 41,5 saniyede kat eder. Böylece geçidin toplam kapalı kalma süresi yaklaşık 46,15 saniye olarak gerçekleşir.

Tablo 2. Tren yaklaşma senaryoları

\begin{tabular}{cccccc}
\hline Durum & İvmeli Hareket & $\begin{array}{c}\text { Sabit Hizla } \\
\text { Hareket }\end{array}$ & $\begin{array}{c}\text { Frenleme } \\
\text { Hareketi }\end{array}$ & $\begin{array}{c}\text { Sabit Hizla } \\
\text { Hareket }\end{array}$ & $\begin{array}{c}\text { Toplam } \\
\text { Kapalı } \\
\text { Süre }\end{array}$ \\
\hline Hiz eğrisi-1 & $450 \mathrm{~m}, 23 \mathrm{sn}$ & $50 \mathrm{~m}, 1,5 \mathrm{sn}$ & $576 \mathrm{~m}, 14,8 \mathrm{sn}$ & $424 \mathrm{~m}, 19 \mathrm{sn}$ & $58,3 \mathrm{sn}$ \\
Hiz eğrisi-2 & $193 \mathrm{~m}, 13,9 \mathrm{sn}$ & $307 \mathrm{~m}, 13,8 \mathrm{sn}$ & $411 \mathrm{~m}, 14,8 \mathrm{sn}$ & $89 \mathrm{~m}, 8 \mathrm{sn}$ & $50,5 \mathrm{sn}$ \\
Hiz eğrisi-3 & $38,6 \mathrm{~m}, 4,6 \mathrm{sn}$ & $461 \mathrm{~m}, 41,5 \mathrm{sn}$ & - & - & $46,15 \mathrm{sn}$ \\
\hline
\end{tabular}

\section{Bulgular ve Tartışma}

\subsection{Tek noktadan hıza duyarlı geçit sistemi tartışma}

UIC otomatik tren kontrolü olan sistemlerde, geçidin hatasız ve emniyetle kapanma bilgisinin ETCS sistemine gönderilmesini tavsiye etmektedir [7]. İncelemeye almış olduğumuz tek noktadan hıza duyarlı geçit modelinde bu bilginin temin edilmesi için yeterli süre ve mesafe 
öngörülmemiştir. Çünkü yarım bariyerli geçit sisteminde bariyerlerin kapanması en az 10 saniye, ayrımlı yollarda dört bariyerli geçitlerde en az 20 saniye sürmektedir. Sonuçta, anklaşman 5 saniyelik süre zarfında geçit bariyerinin emniyetle kapandığını doğrulayamaz. Bu bilgi balis noktasına gönderildiğinde tren balis noktasını önceden geçmiş olacaktır.

UIC'e göre, trenin ön ucu geçide varmadan önce geçit emniyetle kapanmış olmalı ve karayolu araçlarından temizlenmiş olmalıdır [7]. Dolayısıyla bu tasarım geçit bariyerinde bir arıza olması halinde trenin geçide varmadan durdurulmasını garanti edemez.

Tek noktadan hız ölçümü yapan modelde dikkate alınan iki uç durum vardı; en yüksek hızla gelen tren ve en düşük hızla gelen tren. Anahtar soru, düşük hızla gelen bir tren için ne kadar süre gecikme ile geçit etkinleştirilmesi yapılacağıdır.

Demiryollarında sistem tasarımının her zaman en kötü durumda sistemin emniyeti garanti etmesi esastır. Bu nedenle, gecikme süresinin hesabında en düşük hızda gelmekte olan trenin ivmelenme kabiliyeti ve geçide beklenenden çok daha hızlı gelme ihtimali dikkate alınır. Bu yaklaşımla bakıldığında $120 \mathrm{~km} / \mathrm{sa}$ en yüksek sabit hızda geçide yaklaşan tren ile $20 \mathrm{~km} / \mathrm{sa}$ düşük işletmecilik hızı ile geçidi etkinleştirip sonradan ivmelenerek gelen tren arasında geçidin kapalı kalma süresi bakımından sadece 10-11 saniye fark vardır. Ancak toplam kapalı kalma süresindeki küçük azalma miktarına karşın geçide eklenen hız ölçüm sisteminin ve anklaşman bağlantısının hem donanım hem de yazılım bakımından geçit maliyetini katlayarak arttırdığı bilinmektedir.

\section{2. Üç noktadan hıza duyarlı geçit sistemi tartışma}

$\mathrm{Bu}$ model, gerçekte bulunmayan varsayıma dayalı bir modeldir. Ancak modelin sonuçları genellenebilir.

Üç noktadan hız ölçümüne dayanan geçit modelinde; tren üçüncü tespit noktasına (geçide en yakın olan) gelmeden "bariyer kolları kapandı bilgisi" kontrol edilebilir. Bu nedenle en kötü durumda, geçitte bir arıza olması halinde tren geçide gelmeden frenlemeye geçebilir. Üç noktalı model, bu yönüyle tek noktalı hız ölçüm modeline nazaran kısmen daha emniyetlidir.

Üç noktalı modelde bulunan kademeli hız kısıtlama uygulaması ortalama işletmecilik hızını azaltmak suretiyle işletmecilik verimini olumsuz etkiler. Örneğin bu modelde hız eğrisi-1'e (Şekil-4) göre davranan bir tren $1500 \mathrm{~m}$ mesafe içerisinde ortalama $92 \mathrm{~km} / \mathrm{sa}$ hız ile seyir etmektedir. Oysa hız tespit noktalarında hız kısıtlamaları olmasa aynı kabiliyette bir tren $20 \mathrm{~km} / \mathrm{sa}$ başlangıç hızından itibaren serbest ivmelenme hızlanan ve sonra sabit azami işletmecilik hızı 120 $\mathrm{km} / \mathrm{sa}$ hizlanan bir tren, ortalama $98 \mathrm{~km} / \mathrm{sa}$ hızında $1500 \mathrm{~m}$ mesafeyi kat edebilirdi. Her ne kadar $6 \mathrm{~km} / \mathrm{sa}$ ortalama hız farkı, $1500 \mathrm{~m}$ geçit mesafesinde ihmal edilecek kadar az olsa da, azami hızı işletmecilik hızı $160 \mathrm{~km} / \mathrm{sa}$ olan hatlarda bu fark artacaktır.

Ayrıca, hızlanma kısıtlamasının bir hat kesiminde yüzlerce geçitte tekrarlayacağını ve birçok geçidin etkinleşme bölgesinin birbiriyle çakışmakta olduğunu düşündüğümüzde bahse konu modelin ortalama işletmecilik hızına belirgin bir olumsuz etkisi olacaktır. Çünkü bir defa geçit hız kısıdına maruz kalan bir tren ardışık geçit bölgelerini terk edinceye kadar hız kısıt bölgelerinin etkisinden çıkamayabilir. Örneğin çakışan geçit kesimlerinde livre hızı $140 \mathrm{~km} / \mathrm{sa}$ olsa dahi geçit etkinleştirme bölgesinde kalan trenlerin $120 \mathrm{~km} / \mathrm{sa}$ hız üstünde seyrine balisler izin vermez.

Öte yandan, bu modelde frenleme ivmesi düşük olan trenler ivmeli hareketlerde geçide bir süre erken gelebilir. Frenleme ivmesi $0,4 \mathrm{~m} / \mathrm{sn}^{2}$ alındığında ikinci tespit noktasında (geçide $1000 \mathrm{~m}$ ötede) $120 \mathrm{~km} / \mathrm{sa}$ hızda seyreden trenin balisten gelen bilgiyle frenledikten sonra geçide ulaşma süresi yaklaşık 39 saniye olmaktadır. Aynı düşük frenleme ivmesiyle 500 m öteden balisten gelen 
bilgiyle $80 \mathrm{~km} / \mathrm{sa}$ başlangıç hızından frenlemeye başlayan trenin geçide varma süresi ise yaklaşık 31 saniye olmaktadır. Her iki durumda da tren bariyerler indikten sonra geçide ulaşmış olur. Ancak beklenen 45 saniyelik kapalı kalma süresinden daha kısa süre geçidin kapalı kalacağı geçit tasarımında dikkate alınmalıdır. Bu husus özellikle tırların yoğun çalıştığı, hemzemin geçidin birkaç demiryolu hattına birden bastığı durumlarda önemlidir.

ETCS hız kısıtlarına tabi olmayan trenler, yine geçide bir süre erken gelebilir. Bunlara ATS (Automatic Train Stop) sistemi olan trenler örnek gösterilebilir. Dört bariyerli geçitlerde bu bir emniyet zafiyeti oluşturabilir. ETCS'de hıza duyarlı geçit sistemlerine karşı, ATS araç üstü donanımı olan demiryolu araçları kördür. Bu araçların hızlanması engellenemez. ATS'li araçların geçide beklenenden daha kısa sürede ulaşması ihtimali dikkate alınmalıdır. Üç noktadan hıza duyarlı varsayımsal modelde, geçitlerin bu tip araçlarla birlikte kullanımı emniyet zafiyeti oluşturabilir. Örneğin ikinci hız tespit noktasında $20 \mathrm{~km} / \mathrm{sa}$ başlangıç hızından başlayarak 0,4 $\mathrm{m} / \mathrm{sn}^{2}$ gibi düşük bir hızlanma ivmesi ile bir tren üçüncü hız tespit noktasına $74,7 \mathrm{~km} / \mathrm{sa}$ hızla gelir. Bu noktada geçidi etkinleştirdikten sonra balisten gelen hız kısıdını okumayan ve aynı düşük hızlanmaya ivmesi ile hızlanan tren yaklaşık 20 saniyede geçit noktasına ulaşabilir. Bu durum düşük ivme ile hızlanabilen trenlerde dahi en tehlikeli senaryolardan birisinin gerçekleşebileceğini kanıtlar. Bu olasılık Şekil-5'te gösterilmiştir.

Şekil-5'te betimlenen senaryoda dikkate alınan hızlanma ivmesi $0,4 \mathrm{~m} / \mathrm{sn}^{2}$ dir. Daha yüksek bir hızlanma ivmesi dikkate alınırsa böyle bir trenin 20 saniyeden daha kısa zamanda geçit noktasına gelebileceği açıktır. Bu emniyet eksikliğini gidermek için varsayılan etkinleştirme noktası; izin verilen en yüksek tren hızı ve geçit için güvenli kabul edilen en düşük kapalı kalma süresi dikkate alınarak geçit noktasından uzaklaştırılmalıdır. Bu haliyle $500 \mathrm{~m}$ uzaklıkta bir varsayılan etkinleştirme noktası ETCS araçüstü donanımı olmayan trenler için emniyetli değildir.

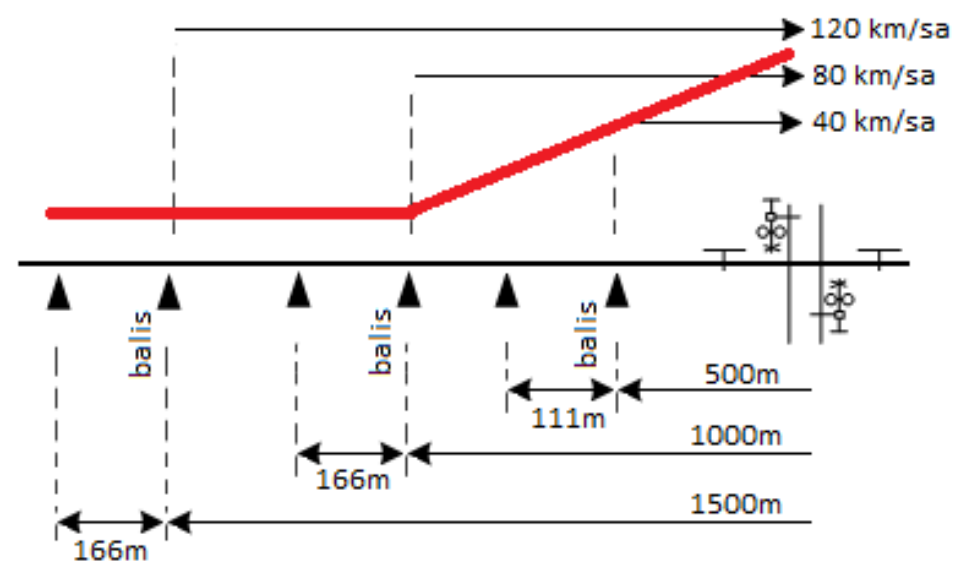

Şekil 5. Hemzemin geçide tehlikeli yaklaşma senaryosunda hız eğrisi

\section{Sonuçlar}

Tek noktadan hız ölçümü uygulanabilir değildir, çünkü azami işletmecilik hızının $120 \mathrm{~km} / \mathrm{sa}$ olduğu hat kesimlerinde geçidin kapalı kalma süresi bakımından en fazla 10-11 saniye kazanç sağlayabilir. Bu kazanım yatırım ve işletmecilik maliyetindeki artışına nazaran ihmal edilecek kadar yetersizdir.

Üstelik hız ölçümümün çok noktadan farklı hız aralıklarına göre yapılıyor olması durumu daha kötüleştirir. Maliyetler ilave sensör ve donanımlarla katlayarak artarken belirgin emniyet zafiyetleri ortaya çıkar. Dolayısıyla farklı tren hızlarına göre geçit etkinleştirme fikri başlangıçta makul görünüyorken ölçülen hızla trenin geçide yaklaşmasının garanti edilemiyor olması tasarımı 
karmaşıklaştırır. Trenlerin belli hızlarda yaklaşmasını garanti etmek için tren koruma sistemlerinin kurulması zorunlu hale gelir. Bu, hem aşırı maliyetli bir çözümdür hem de araç üstü tren koruma sistemi olmayan trenler için kaçınılmaz olarak emniyet zafiyeti oluşur.

Örneğin, üç noktadan hız ölçümüne dayanan geçit sistemi geçidin her iki tarafi dikkate alındığında en az 6 adet hız ölçüm aygıtı, balis bileşeni ve bunların anklaşmanla bağlantısını gerektirir. Kurulum ve bakım maliyetleri kat kat yüksek ve tasarımı karmaşık bir yapıdır.

$\mathrm{Bu}$ model, geçidin kapalı kalma süresi bakımından belirgin bir kazanım sağlayabilir. Ancak, ETCS donanımı olmayan dolayısıyla hız kısıtlarına uymayan yahut ETCS araçüstü donanıma sahip fakat frenleme ivmesi düşük trenlerin hatta kullanılması halinde kazalara sebebiyet verecek emniyet açıkları oluşturmaktadır. Bu yönüyle, üzerinde çalışılan ve üç noktadan hız ölçümüne dayanan geçit modeli uygulanabilir değildir.

Çok noktadan veya tek noktadan hız ölçümüne dayanan ETCS geçit uygulamaları anklaşman bağlantısı ve yazılım gerekliliği nedeniyle üzerinde değişiklik yapılması (yer değişikliği v.b.) etkilere karş1 esnek bir model değildir. Eğer ilerde "deplase" gibi bir üst yapı değişiklik kararı alınırsa yapılan pahalı yatırım kaybedilmiş olacaktır.

\section{5. Öneriler}

Tek noktadan veya çok noktadan hız ölçümüne dayalı geçit sistemlerinin kullanımı uygulanabilir değildir. Geleneksel geçit sisteminin daha kısa süreli kapanması başka yöntemlerle daha ekonomik ve daha etkili biçimde sağlanabilir.

Örneğin, geçit tasarımında hattın azami işletmecilik hızı yerine geçidin bulunduğu hat kesiminin statik hız profili dikkate alınarak kapalı kalma süresi bir süre kısaltılabilir. Çünkü çoğu yerde yolun statik hız profili $80 \mathrm{~km} / \mathrm{sa} \mathrm{h} ı$ değerinin altındadır. Buralarda trenlerin daha yüksek hızlarda gelmesi beklenmez. Statik hiz profili $80 \mathrm{~km} / \mathrm{sa}$ olan bir demiryolu kesiminde 45 saniyelik kapanma süresini sağlamak için geçit etkinleştirme noktası 1000 m'ye kurulabilir. Böylelikle yolcu ve yük renlerinin 1500 m yerine 1000 m'den geçidi etkinleştirmesi sağlanır. Bu yaklaşım, noktasal hız ölçümüne nazaran çok daha basit, etkili ve geleneksel geçit tasarımına uygun bir seçenektir.

Geleneksel geçit tasarımının yanı sıra hemzemin geçit koruma sinyali gerektiren ve arıza halinde geçitten önce treni durdurmayı hedefleyen geçit tasarım modelleri de bulunaktadır. Bu modeller ayrı bir çalışma kapsamında incelenerek emniyet yönünden değerlendirilecektir.

Noktasal hız ölçümüne dayanan geçitlerin yüksek kurulum maliyetlerinin yanı sıra yüksek işletmecilik maliyetleri de dikkate alındığında demir yolu alt/üst geçidi yapılması ekonomik bakımından uygulanabilir hale gelebilir. Demiryolu alt/üst geçitlerinin emniyet ve işletmecilik verimi bakımından en iyi çözüm olduğu kuşkusuzdur. Demiryolu alt geçit/üst geçitleri için yapılan harcamaların inşaat işleri üzerinden tümüyle ülkemizde kalacağı, ETCS sisteminde dayalı hemzemin geçitlerde ise yatırım kaynaklarının neredeyse büyük ölçüde yurt dışına gideceği dikkate alınmalıdır.

Bu sebeplerle, hıza duyarlı hemzemin geçitler yerine öncelikle yol alt/üst geçitlerinin yapılması, bu mümkün değilse daha basit ve geçit noktasında statik hız profiline dayalı olarak kapalı kalma süresi kısaltılmış emniyetli geçit modellerinin uygulanması önerilmektedir. 


\section{Kaynakça}

[1] S. Erdoğdu, A. Dikmen, "Demiryolu hemzemin geçitleri risk ölçüm modeli," 11.Ulaştırma Kongresi, TMMOB İnşaat Mühendisleri Odası, İstanbul, 2015

[2] O. Deniz, "Karayolu-Demiryolu Geçitlerinin Planlanması", Yüksek Lisans Tezi, Fen Bilimleri Enstitüsü, İstanbul Teknik Üniversitesi, İstanbul.

[3] R. Bozalioğlu and E. A. Öztürk, "Hemzemin geçitlerde alt/üst geçit iyileştirmelerinin belirlenmesi," Uludağ University Journal of The Faculty of Engineering , vol.24, no.1, pp.243-252, 2019, doi.org/10.17482/uumfd.425489

[4] Ş. Yıldırım et al., "Analysis experimental intelligent railway level crossing system," International Journal of Emerging Technology and Advances Engineering, vol.5, no.4, pp.1-5, 2015

[5] C. Bildirici, "Hemzemin geçit erken uyarı sistemi (HEGEUS)", Demiryolu Mühendisliği, sayı. 3, ss. 70-74, Haz. 2016

[6] F. Sarıkoç, "ERTMS ETCS Trafik kontrol sistemleri ve deneyimler", Demiryolu Mühendisliği, sayı. 3, ss. 61-69, Haz. 2016

[7] Guidence on the automatic operation of level crossings, UIC code 761, $4^{\text {th }}$ edition, January 2004

\section{Özgeçmiş}

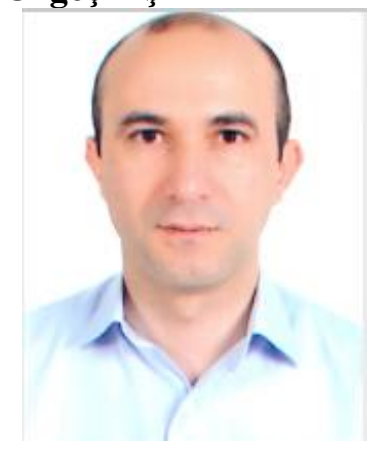

\section{Fatih SARIKOÇ}

1978 y1lında doğmuştur. 1995 y1lında Demiryolu Meslek Lisesi'nden mezun olmuştur. 1996-2021 yılları arasında TCDD bünyesinde sirasıyla sürveyan, mühendis, yüksek mühendis, proje müdürü ve daire başkan yardımcılığı görevlerinde bulunmuştur. Lisans eğitimini ERÜ Kontrol ve Bilgisayar Mühendisliği Bölümünde, yüksek lisans ve doktora öğrenimini ERÜ Fen Bilimleri Enstitüsü Bilgisayar Mühendisliği alanında tamamlamıştır.

E-Posta: fsarikoc@erciyes.edu.tr

\section{Beyanlar:}

Bu makalede bilimsel araştırma ve yayın etiğine uyulmuştur. 